Revista de Estudios Histórico-Jurídicos

[Sección historia del derecho chileno]

XLII (Valparaíso, Chile, 2020)

[pp. 477-498]

\title{
LA JUSTICIA LOCAL E ILETRADA DEL CHILE DECIMONÓNICO (1817-1875): EL CASO DEL MANUAL O INSTRUCCIÓN PARA LOS SUBDELEGADOS E INSPECTORES EN CHILE*
}

[The local and illiterate justice of decimononic Chile (1817-1875): The case of the "Manual or instruction for the sub-delegates and inspectors in Chile"]

\section{Roberto CERÓN ReYes**}

Universidad de Chile y Universidad de los Andes, Chile

Nicolás GIRÓN ZÚNIGA***

Pontificia Universidad Católica de Chile y Universidad Nacional Andrés

Bello, Chile

\section{RESUMEN}

El artículo examina el Manual o instrucción para los subdelegados e inspectores en Chile, dirigido a instruir y controlar a la justica local e iletrada del Chile decimonónico. En el primer apartado se detallan algunos aspectos de la organización judicial entre 1817 y 1875 , época donde conviven elementos del orden jurídico indiano con aquellos del incipiente orden jurídico republicano. Se pone especial énfasis en las figuras de los subdelegados e inspectores, así como también se informan asuntos relativos al nombramiento y control de estos jueces.

\section{Abstract}

The article examines the Manual or Instruction for Subdelegates and Inspectors in Chile, aimed to instruct and control the local and illiterate justice in nineteenthcentury Chile. The first section details some aspects of judicial organization between 1817 and 1875, a time when elements of the Spanish colonial law coexist with those of the incipient republican legal order. Special emphasis is placed on the sub-delegates and inspectors, as well as matters related to the appointment and control of these judges.

* Se han actualizado al castellano actual las fuentes citadas a lo largo del presente trabajo.

** Profesor asistente, Facultad de Derecho, Universidad de Chile. Profesor de Historia del Derecho e Historia de las Instituciones de Chile, Facultad de Derecho, Universidad de los Andes, Chile. Alumno y becario del Doctorado en Derecho de esta última casa de estudios. Contacto: roberto.ceron@derecho.uchile.cl

*** Profesor de Historia de Chile, Instituto de Historia, Pontificia Universidad Católica de Chile. Profesor de Historia del Derecho, Facultad de Derecho, Universidad Nacional Andrés Bello. Doctor (C) en Historia, Pontificia Universidad Católica de Chile. Contacto: njgiron@uc.cl 
En relación a este último punto, en el segundo apartado se estudia el texto ya referido, especialmente sus ediciones, motivaciones jurídicas y extrajurídicas, así como su contenido. Se sostiene que el éxito o fracaso del Manual es algo que aún es discutible, asunto que no obsta a afirmar la preocupación del Estado por controlar y reformular la práctica judicial local, muchas veces apartada del legalismo que se pretendía implantar.

\section{Palabras clave}

Judicatura - Estado - subdelegados - inspectores - justicia local - justicia iletrada - práctica forense - control administrativo - control judicial - literatura jurídica.
In relation to this last point, in the second section, the text already referred is studied, especially its editions, legal and extra-legal motivations, as well as its content. It is argued that the success or failure of the Manual is something that is still debatable, a matter that does not prevent affirming the State's concern to control and reformulate local judicial practice, often separated from the legalism that was intended to be implemented.

RECIBIDO el 31 de octubre de 2019 y ACEPTADO el 20 de mayo de 2020

\section{INTRODUCCIÓN}

En este trabajo nos hemos propuesto presentar y revisar algunos aspectos de una fuente aún no estudiada en toda su magnitud por la historiografía. Nos referimos al Manual o instrucción para los subdelegados e inspectores en Chile [en adelante, el Manual] ${ }^{1}$, el que tuvo múltiples ediciones a lo largo del siglo XIX. En lo que aquí respecta, cobra especial relevancia porque sirvió para, o pretendió, controlar el actuar de subdelegados e inspectores, sin perjuicio de otros fines (instruir a estos jueces legos; facilitarles el ejercicio de su cargo; y la pretensión gubernativa de lograr la uniformidad en la aplicación de la ley). Además, se enmarca en la corriente de literatura jurídica práctica que hunde sus raíces en el espíritu ilustrado del periodo monárquico e, incluso, más allá, y que se proyecta hacia la época republicana. Creemos que se trata de un documento que cobra interés tanto para historiadores del derecho como para quienes se interesan por el estudio histórico de la justicia en clave sociocultural. Para los primeros, porque da cuenta de la puesta en práctica de la organización judicial chilena en un nivel local, rasgo todavía olvidado y que no ha merecido la atención correspondiente. Para los segundos, porque informa una de las tantas aristas de la justicia local y su operatividad, lo que se complementa con aspectos ya develados por la historia sociocultural de la justicia, respecto a las condiciones en que esta se practicaba en las comarcas distantes de la capital durante el periodo señalado.

Para entender y situar el lugar de los subdelegados e inspectores en la judicatura del siglo XIX, así como el rol que cumplió el Manual, creemos adecuado

${ }^{1}$ ANÓNimo. Manual o instruccion para los subdelegados e inspectores en Chile. (3a ed., Santiago, Imprenta del Ferrocarril, 1860) [visible en internet: https://archive.org/details/b28749807/]. 
ilustrar, aunque sea en términos generales, las características más relevantes de la organización judicial entre 1817 y 1875, así como la dependencia dual de estas dos clases de jueces con el aparato judicial y la administración, cuestión que se abordará en la primera sección de este trabajo. Como se verá, el fin de la monarquía y el advenimiento de la república, no habrían significado una ruptura total entre las formas de hacer justicia entre uno y otro periodo, cuestión que realza en cierto modo la orientación de estos instructivos.

En un segundo apartado, nuestro foco se centra en el texto, sus ediciones, características principales y, particularmente, cómo dicha instrucción fue perfilando el papel de la justicia de menor cuantía que operaba -fundamentalmente- en los espacios rurales y pequeñas villas del Chile del siglo XIX, lo que significó hacer frente a un estilo y forma de hacer justicia que se arrastraba desde el periodo indiano. Se reflexiona aquí sobre cómo los temas tocados en él dan cuenta de la preocupación del Estado chileno por promover reformas al arbitrio judicial, en tanto desapego a la legalidad que se fue imponiendo en el proceso de construcción estatal republicano, y a los supuestos excesos y abusos cometidos por subdelegados e inspectores.

Pese a su vasta distribución e impresión entre los años 1845 y 1877, una hipótesis sencilla de trabajo sugiere que el éxito o fracaso del Manual (y sus diferentes versiones) es algo que aún se discute, debido a múltiples razones, ya sea por limitaciones propias de la institucionalidad o bien, por la resistencia que opusieron los propios subdelegados e inspectores. No obstante, sugerimos que la importancia del estudio de esta fuente, más allá de dicho éxito o fracaso, permite dar cuenta de la preocupación del Estado por controlar y reformular la práctica judicial local, que muchas veces se apartaba del legalismo que se pretendía implantar.

Además del análisis propio del opúsculo, hemos recurrido a otras fuentes histórico-jurídicas, tales como las memorias ministeriales, las leyes dictadas en el periodo, las visitas judiciales y ciertos expedientes de archivo que dan cuenta de algunas dificultades propias del proceso aquí descrito. También, estas fuentes dialogan con la amplia bibliografía tanto de la historia del derecho como de la justicia, cuya consulta se torna indispensable a la hora de ofrecer un enfoque que amalgame ambas orientaciones historiográficas.

\section{LA ORGANIZACIÓN DE LA JUDICATURA ENTRE 1817 Y 1875}

La desarticulación de la monarquía hispano-indiana a contar de 1810 y el cese definitivo de la Real Audiencia de Santiago en febrero de 1817, no supuso una reestructuración abrupta y total de la judicatura chilena. Al contrario, tanto en materia judicial y jurídica se aprecia, según se ha investigado, una cierta continuidad y persistencia entre el pasado indiano y la naciente organización republicana² Desde la época de la monarquía borbónica e ilustrada -siglo XVIII-, se impuso

${ }^{2}$ La persistencia en materia jurídica es advertida, entre otros, por GUZMÁN BRITO, Alejandro, La codificación civil en Iberoamérica (Santiago, Editorial Jurídica de Chile, 2000), p. 186. Para el caso de las instituciones judiciales, últimamente véase DougnaC, Antonio; Cerón, Roberto, Una silueta de la judicatura chilena en el siglo XIX, en BAChH. 125 (Santiago, 2016), pp. 8 ss. 
al orden jurisdiccional indiano una marcada distinción entre la esfera de justicia y la de gobierno ${ }^{3}$. La primera estructurada en oficios, mientras que la segunda fue montada en oficinas ${ }^{4}$.

La institucionalidad judicial indiana se acomodó en el sistema republicano, de modo que la Real Audiencia fue sucedida por una Corte de Apelaciones, ubicada en Santiago ${ }^{5}$, y la justicia lega, es decir, iletrada, se mantuvo en pie hasta bien entrada la segunda mitad del siglo $\mathrm{XIX}^{6}$. Esta última, estuvo radicada en subdelegados e inspectores.

Como atributos completamente nuevos en este proceso de cambio figuran la erección de la Corte Suprema de Justicia en 1823 y el intento de instalar en todo el territorio de la república una justicia de carácter letrada, esto es, a cargo de jueces con estudios de derecho ${ }^{7}$, tarea nada fácil en el curso del siglo XIX ${ }^{8}$. Además, puede señalarse la reconfiguración de las atribuciones del máximo tribunal en materia de protección a los gobernados ${ }^{9}$; la ampliación de la órbita de acción de la administración, lo que supuso colocar a la judicatura en muchos aspectos, bajo

\footnotetext{
${ }^{3}$ Bravo, Bernardino, Judicatura e institucionalidad en Chile (1776-1876): del absolutismo ilustrado al liberalismo parlamentario, en REHJ., 1 (1976), pp. 61-87.

${ }^{4}$ Ibíd., p. 67: "La competencia se radica de manera estable en la oficina como tal, independientemente de la persona de su jefe, en lugar de confundirse, como antes, al titular de cada oficio por el tiempo de su desempeño".

${ }^{5}$ Barrientos, Javier, La Real Audiencia de Santiago de Chile (1605-1817). La institución $y$ sus hombres (Madrid, Fundación Histórica Tavera, 2000), pp. 130 ss.; NAVARro, Enrique, La judicatura chilena del absolutismo ilustrado al Estado constitucional. De la Real Audiencia a la Corte de Apelaciones de Santiago (Memoria de Prueba para optar al Grado de Licenciado en Ciencias Jurídicas, Santiago, Facultad de Ciencias Jurídicas y Sociales de la Universidad de Chile, 1988), pp. 5 ss.
}

${ }^{6}$ BRANGIER, Víctor, Transacciones entre ley y prácticas judiciales locales en tiempos de codificación. El caso de la visita judicial nacional. Chile, 1848-1849, en Revista SudHistoria, 5 (Valdivia, 2012), p. 127.

${ }^{7}$ Recién en el gobierno de José Manuel Balmaceda, por ley de 3 de febrero de 1888, se declaró que cada departamento del país contara con un juez letrado. Anguita, Ricardo, Leyes promulgadas en Chile desde 1810 hasta el $1^{\circ}$. De junio de 1912 (Santiago, Imprenta, Litografía i Encuadernación Barcelona, 1912), III, pp. 70-71.

${ }^{8}$ Esto no fue fácil. De hecho, durante el siglo XIX, y hasta antes de 1888 se fundaron relativamente pocos juzgados de letras. Al respecto, véase TISI, Ricardo, Regulación de la judicatura chilena entre 1810 y 1875 (Memoria de Prueba para optar al Grado de Licenciado en Ciencias Jurídicas, Santiago, Facultad de Ciencias Jurídicas y Sociales de la Universidad de Chile, 1993), pp. 8-11. Bıьот, Pauline, Construyendo un esquema de la administración de justicia: fuentes, métodos y resultados. Chile, siglo XIX, en Revista Historia y Justicia 1, (Santiago, 2013), p. 14. [visible en internet: http://revista.historiayjusticia.org/dossier/justicia-control-y-territorio/construyendoun-esquema-de-la administracion-de-justicia-fuentes-metodo-y-resultados-chile-siglo-xix/]

${ }^{9}$ Nos referimos a la actuación a gravamine. Hasta la Constitución de 1823 pervivieron, principalmente a través del recurso de apelación, los recursos indianos de protección frente a los actos de gobierno. En dicho año esta desaparece. Únicamente la Corte Suprema estaría en condiciones de reclamar ante el gobierno, pues a ella correspondía, según los artículos 116 y 144 de la Constitución de 1823, "proteger, hacer cumplir y reclamar a los otros poderes por las garantías individuales y judiciales", facultad amputada en 1875, con la dictación de la Ley de Organización y Atribuciones de los Tribunales. Véase BARRIENTOS, Javier, Regimenes de excepción y recursos de protección ante la jurisprudencia chilena, -Anexo II-, en PeÑA, Carlos (ed.), Práctica 
su sujeción ${ }^{10}$; y la maduración, a lo largo de este siglo, del legalismo racionalista que inspiró a la codificación y al constitucionalismo decimonónicos, que obligó a los jueces, a partir de febrero de 1837, a fundar sus sentencias ${ }^{11}$. Este último rasgo convivió con el arbitrio judicial durante todo el periodo que estudiamos, e incluso más ${ }^{12}$.

En suma, "este fue un período de consolidación del sistema judicial chileno, marcado por la dictación de una serie de disposiciones que lo fueron dotando de fisonomía propia. Así, las reformas orgánicas a la judicatura cobran mayor sistematización mediante los textos constitucionales de 1818 y 1822 y particularmente a través de la frustrada Constitución moralista de 1823, el Reglamento de Administración de Justicia de 2 de junio de 1824, las Leyes Marianas, la Ley sobre nombramiento de jueces de 30 de diciembre de 1842 y la Ley de Organización y Atribuciones de los Tribunales de 1875, entre otras disposiciones" ${ }^{13}$. En otras palabras, el periodo 1817-1875 supuso la reestructuración de buena parte del orden judicial heredado de la monarquía hispano indiana, marcada por las innovaciones que exigía la afirmación del Estado constitucional de las constituciones escritas (vgr. consagración de la idea de separación de poderes, creación de un tribunal supremo y el imperio sin contrapesos de la ley). Dicha reestructuración, eso sí, coexistió con un sinnúmero de aspectos, ideas, valoraciones e institutos de la época indiana. Tal fue el caso, por ejemplo, de la persistencia del arbitrio judicial y la justicia lega ${ }^{14}$.

Pese a su corta duración, la Constitución de 1823 instituyó a la judicatura

constitucional y derechos fundamentales (Santiago, Corporación Nacional de Reparación y Reconciliación, 1996), pp. 353-423.

${ }^{10}$ Bravo, Bernardino, Judicatura, cit. (n. 3), p. 79. Bilot, Pauline; Whipple, Pablo, Los desafios de la justicia republicana. Profesionalización e independencia de la judicatura en Chile y Perú durante el siglo XIX, en De Francesco, Antonino; Mascilli Migliorini, Luigi; Nocera, Raffaele (coords.), Entre Mediterráneo y Atlántico. Circulaciones, conexiones, miradas, 1756-1867 (Santiago, Fondo de Cultura Económica, 2014), pp. 490-499.

${ }^{11}$ Se trata de una de las "leyes marianas". Véase Anguita, Ricardo, cit., (n. 7), I, p. 49. LORENTE, Marta, Reducción de la justicia, emergencia de la administración (España, 1810-1870). Una reflexión iushistori[o]gráfica, en RChHD., 22 (2010), I, pp. 338-340. Sobre dichas leyes, Figueroa, María Angélica, La codificación civil chilena y la estructuración de un sistema jurídico legalista, en Congreso Internacional Andrés Bello y el Derecho (Santiago, Editorial Jurídica de Chile, 1981), pp. 86 ss.

${ }^{12}$ Brahm, Enrique, ¿Jurisprudencia creativa? La Corte Suprema de Justicia 1841-1860, en RChHD., 16 (1990), pp. 565-566.

${ }^{13}$ Dougnac, Antonio; Cerón, Roberto, cit. (n. 2), pp. 101-111. Stabili, María Rosaria, Jueces y justicia en el Chile liberal, en CARMAGNANI, Marcello (coord.), Constitucionalismo y orden liberal. América Latina, 1850-1920 (Roma, Otto Editore, 2000), pp. 227-258.

${ }^{14}$ Para el caso de la convivencia entre justicia lega y letrada en Argentina, en el período 18201853, véase TAU, Víctor, La administración de justicia en las provincias argentinas (1820-1853). Planteo preliminar para su estudio, en Revista de Historia del Derecho, 1 (Buenos Aires, 1973), pp. 206-213 y 239-249. Sobre el arbitrio judicial en Chile BRAVO, Bernardino, Arbitrio judicial y legalismo. El juez frente al derecho antes y después de la codificación en Europa e Iberoamérica, en Él Mismo, El juez entre el derecho y la ley, en el mundo hispánico. Del Estado de Derecho al derecho del Estado (siglos XVI a XXI) (Santiago, LexisNexis, 2006), pp. 361-375. BraHm, Enrique, cit. (n. 12), passim. 
de un orden jerárquico y piramidal que, incluso, se observa hasta hoy. La Corte Suprema se erigió como "primera magistratura judicial del Estado" ${ }^{15}$ y recayó sobre ella la "superintendencia directiva, correccional, económica y moral ministerial, sobre los tribunales y juzgados de la Nación... [y] también la de la policía criminal [...]"16. Asimismo, convivió con la única Corte de Apelaciones de la época, situada en Santiago ${ }^{17}$.

El resto de los tribunales de la república se fijó a partir del Reglamento de Administración de Justicia de 1824 . Este cuerpo legal complementó a la mencionada carta constitucional y reguló otras materias propias de la organización judicial. En él se reglamentaron los tribunales inferiores del país, constatándose que la gran mayoría de la resolución de los asuntos judiciales recayó en personas que no poseían estudios de derecho, es decir, jueces legos. Únicamente el juez de letras debía ser abogado, pero en la práctica eran muy pocos y, en consecuencia, donde no los había, tal cargo lo ejercían los alcaldes ordinarios ${ }^{18}$. Es decir, la justicia inferior estuvo prácticamente dominada por jueces sin formación jurídica, específicamente alcaldes ordinarios, inspectores y subdelegados. Asimismo, se trataba de una característica, al parecer, común a buena parte de los países desgajados de la monarquía hispano indiana ${ }^{19}$. Esta cualidad motivó una serie de acciones encaminadas a controlar su actuar, según se verá.

La justicia de menor cuantía recaía, por lo general, en inspectores y subdelegados. A partir del mencionado reglamento, en el concepto de menor cuantía participan tres subclases, sosteniéndose que: "Toda demanda civil que no exceda de cuarenta pesos se interpondrá ante el inspector de la comunidad a que perteneciere el demandado. Si la cuantía de la demanda no llegare a doce pesos se ejecutará lo que el inspector dispusiere" ${ }^{20}$. De ambas subclases conocían los inspectores, mientras que el conocimiento de los asuntos comprendidos en la tercera subclase se encontraba radicado en los subdelegados. A este respecto, el reglamento señala que "Toda demanda civil que excediere de cuarenta pesos y no pasare de ciento cincuenta; y toda demanda criminal sobre injurias o faltas livianas que no merezcan otra pena que alguna represión o arresto ligero, se interpondrá ante el prefecto a que perteneciere la comunidad del demandado, quien decidirá verbalmente, pudiendo la parte que se reputare agraviada apelar ante el subdelegado respectivo" 21 . Dicha disposición debe complementarse con lo preceptuado por el Manual, que señala la intervención de los subdelegados en tales asuntos. Estos eran autoridades gubernativas de las unidades político administrativas en que se dividían los departamentos provinciales conocidas como subdelegaciones, mientras que los inspectores fueron, además de

${ }^{15}$ Constitución de 1823. Título XIII, artículo 143, en VALENCIA, Luis, Anales de la República (2a ed., Santiago, 1986), I, p. 133.

${ }^{16}$ Ibíd., p. 134.

${ }^{17}$ A lo largo del siglo XIX se fundaron las siguientes Cortes: Concepción (1849), La Serena (1849), Iquique (1884), Talca (1888), Valparaíso (1891) y Valdivia (1906), en DougnaC, Antonio; Cerón, Roberto, cit. (n. 2), pp. 39-43.

${ }^{18}$ Artículo 46 del Reglamento. Texto en Anguita, Ricardo, cit. (n. 7), I, p. 154.

${ }^{19}$ Para el caso de Argentina y sus provincias véase TAU, Víctor, cit. (n. 14), passim.

${ }^{20}$ Artículo 1 del Reglamento. Texto en Anguita, Ricardo, cit. (n. 7), I, p. 151.

${ }^{21}$ Artículo 2 del Reglamento, ibíd., p. 151. 
jueces de menor cuantía, “jefes políticos y policiales de las prefecturas, división final de las subdelegaciones" 22 . Su origen se remonta a la implantación del régimen de intendencias aplicado en los territorios del reino de Chile por la Ordenanza de Intendentes de $1786^{23}$. Ahí figura dicho cargo que, en la práctica, sucedió al de corregidor de la época indiana. Este mero cambio en la denominación es resaltado en el "Expediente formado sobre el nuevo Establecimiento de la Superintendencia General de Real Hacienda, e Intendencias del Reino de Chile” de 1787, que señala: "En esta parte nada varía el nuevo sistema, sino el nombre de Subdelegados con que se conocerán ahora los que se han titulado Corregidores" ${ }^{24}$. Como dijéramos, desempeñaron sus tareas en las subdelegaciones que sustituyeron a los antiguos corregimientos o partidos ${ }^{25}$. Respecto a los inspectores, únicamente estamos en condiciones de afirmar que aparecieron en el Reglamento de Administración de Justicia de 2 de junio de 1824 .

Según hemos dicho supra, subdelegados e inspectores dependían tanto del poder judicial como del ejecutivo, pues realizaban funciones asociadas a ambas ramas del Estado. Junto con impartir justicia de menor cuantía, cumplían labores administrativas y de resguardo del orden público local, "ejerciendo las funciones de policía rural en la vigilancia poblacional y persecución del crimen" ${ }^{26}$. Ello denota la íntima relación entre la judicatura y el gobierno. El nombramiento de dichos jueces era de exclusiva responsabilidad de la primera magistratura del país. En efecto, el gobernador, cargo cuya designación dependía del presidente a sugerencia del intendente, era quien elegía a los subdelegados. A su vez, estos últimos designaban a los inspectores del distrito, previa anuencia de sus "superiores jerárquicos”27. De ahí surge la afirmación de algunos autores en torno a que

${ }^{22}$ BRANGIER, Víctor, Saber hacer y decir en justicia. Culturas juridico judiciales en la zona centro-sur de Chile (1824-1875) (Rosario, Prohistoria, 2019), p 37. De acuerdo con el artículo 190 de la Constitución de 1823 "El Estado se divide gradualmente en gobiernos departamentales, delegaciones, subdelegaciones, prefecturas e inspecciones", texto en VALENCIA, Luis, cit. (n. 15), p. 139.

${ }^{23}$ Dougnac, Antonio; Cerón, Roberto, cit. (n. 2), p. 28. Enríquez, Lucrecia, Los jueces diputados y los distritos judiciales borbónicos en Chile (1786-1818), en RChD., 43/2, (Santiago, 2016), p. 651.

${ }^{24}$ Citado en EnríQuez, Lucrecia, cit. (n. 23), p. 652.

${ }^{25}$ Dougnac, Antonio, Manual de historia del derecho indiano (México, MacGraw-Hill, 1998), p. 157.

${ }^{26}$ BrangIer, Víctor, Saber hacer y decir en justicia, cit. (n. 22), p. 50. Para las atribuciones de subdelegados e inspectores véase la Ley de Régimen Interior, de 10 de enero de 1844. Texto en Anguita, Ricardo, cit. (n. 7), I, pp. 432-435. Para la configuración del régimen de administración de justicia en Buenos Aires en el periodo 1853-1881, que en esta materia tiene características parecidas al chileno revísese CoRva, María Angélica La administración de justicia en la provincia de Buenos Aires, 1853-1881. (Tesis de posgrado. Universidad Nacional de La Plata. Facultad de Humanidades y Ciencias de la Educación, 2013). [visible en internet: http:// www.memoria.fahce.unlp.edu.ar/tesis/te.878/te.878.pdf]

${ }^{27}$ Palma, Daniel, Los jueces del orden. Estructura y funciones de la justicia bajo dos regímenes autoritarios: Buenos Aires y Chile, 1829-1852, en PinTo, Julio; Palma, Daniel; Donoso, Karen; Pizarro, Roberto, El orden y el bajo pueblo. Los regímenes de Portales y Rosas frente al mundo popular, 1829-1852 (Santiago, Lom Ediciones, 2015), p. 89. Idéntica aseveración en BiLOT, Pauline; Whipple, Pablo, cit. (n. 10), p. 486. 
"buena parte de la administración de justicia recayó en el personal subalterno de los departamentos, subdelegaciones y distritos"28.

En cuanto al control de estas judicaturas, el panorama es más complejo y difuso. A través de distintas prácticas intervenía tanto el poder judicial como el ejecutivo, aunque mayormente este último. También se ha señalado que ciertos sectores de la sociedad hicieron lo suyo ante los jueces legos. Así: "tanto las autoridades políticas (intendentes y gobernadores), los jueces letrados y los grandes propietarios (hacendados y mineros), intentaron influenciarlos y a la vez controlarlos en provecho de sus fines e intereses, lo que entorpeció la administración de justicia propiamente tal" 29 .

A propósito del control ejercido por el gobierno, desde el Ministerio de Justicia se formularon mecanismos para intervenir el actuar de los jueces legos, tales como penalización de prácticas erróneas, fiscalización de su labor a través de las visitas y su instrucción. El 25 de septiembre de 1837 se promulgó la ley de denegación de justicia que intentó poner a raya algunas de las conductas abusivas de estos jueces. Por su parte, las visitas judiciales también buscaron informar sobre el estado de la administración judicial en el país en aras de una futura reforma, y la enmienda de errores y abusos detectados. Eran de tres tipos: nacional, provincial y departamental. Representaron el medio por el que los jueces de letras se relacionaban y fiscalizaban el actuar de los jueces legos ${ }^{30}$. Prueba de ello fue la Visita Judicial Nacional practicada por Antonio Varas entre 1848 y 1849 y las conclusiones obtenidas, que giran en torno a esta temática ${ }^{31}$. Finalmente, en lo que toca a su formación, en el año 1842, durante el gobierno de Manuel Bulnes, el ministro de Justicia Manuel Montt presentó una cartilla de derecho para jueces legos, con el fin de instruirlos sobre cuestiones jurídicas elementales y de tramitación judicial (derecho procesal), denominado "Manual o instrucción para los subdelegados e inspectores en Chile".

${ }^{28}$ Palma, Daniel, cit. (n. 27), pp. 89-90. Idéntica aseveración en Bilot, Pauline; Whipple, Pablo, (n. 10), p. 486.

${ }^{29}$ Palma, Daniel, cit. (n. 27), p. 90. Para efectos de la idea de control, asimilamos su significado al término "vigilancia". Si se revisan los diccionarios históricos de la Real Academia Española, la acepción "control" no figura en los textos editados durante el siglo XIX, mas sí la acepción vigilar y sus derivados (vigilancia, vigilante, vigilantemente, vigilantísimo). Así, "vigilancia" supone "cuidado y atención exacta en las cosas que están a cargo de cada una". Véase Real Academia Española, Diccionario de la lengua castellana por la Real Academia Española. Novena edición (Madrid, Imprenta de D. Francisco María Fernández, 1843), p. 744, 2. [visible en internet http://ntlle.rae.es/ntlle/SrvltGUIMenuNtlle? $\mathrm{cmd}=$ Lema\&sec=1.1.0.0.0.]

${ }^{30}$ BiLot, Pauline; Whipple, Pablo, cit. (n. 10), pp. 488-489.

${ }^{31}$ Brangier, Víctor, Transacciones, cit. (n. 6), passim. Westermeyer, Felipe, Derecho indiano $y$ derecho patrio en las "Memorias" de los Ministros de Justicia de Chile (1839-1873), en REHJ., 32 (2011), pp. 548-549. 


\section{SOBRE El MANUAL DE INSTRUCCIÓN PARA LOS SUBDELEGADOS E INSPECTORES EN CHILE}

\section{Sobre las ediciones del Manual y sus fines}

Como hemos expresado, el texto fue publicado por primera vez en 1845, tratándose -al parecer- de su primera edición. Su extensión fue de cuarenta páginas y conoció varias ediciones ${ }^{32}$. Respecto a que el texto de 1845 sea efectivamente la primera edición, es algo que puede comprobarse mediante dos vías. Una de ellas es a través de las Memorias Ministeriales del Ministerio de Justicia, Culto e Instrucción Pública, donde existen referencias concluyentes sobre el asunto. En efecto, la Memoria del año 1842, junto con denunciar una serie de abusos y vicios en la administración de justicia, informa que: "Los jueces de menor cuantía, elegidos las más veces de entre personas que no han visto ni la ley que les autoriza para juzgar, son los que con más frecuencia cometen abusos que dan origen a quejas y reclamos. El Gobierno ha creido de suma urgencia proporcionar a estos últimos los medios de expedirse con acierto, y con esta mira ha dispuesto que se forme un prontuario o manual en que se encuentren recopiladas, con las explicaciones convenientes, todas las leyes y disposiciones que puedan suministrarles la debida instrucción"33.

El afán por instruir a los jueces de menor cuantía se funda, primeramente, en el absoluto desconocimiento de la ley que debían aplicar. De acuerdo con Brangier, existía un interés del gobierno por conminar a estos jueces a usar el derecho legislado frente a las prácticas y costumbres judiciales locales ${ }^{34}$. Es decir, el objetivo primario de este texto habría sido el de constituir una pauta para jueces no formados en derecho (legos), con la función de servirles de guía, para "uniformar su acción y, sobre todo, ajustarla a derecho escrito" 35 . Ambas motivaciones son cardinales si se atiende a la forma en cómo se organizaba la justicia en el Chile decimonónico. Como dijimos, subdelegados e inspectores constituían la base de la justicia local, que predominó en Chile hasta bien entrado el siglo XIX ${ }^{36}$, bajo el paraguas de una sociedad marcadamente rural y tradicionalista.

Por otra parte, se ha asegurado que tanto este tipo de instructivos como otras

${ }^{32}$ Bilot, Pauline; Whipple, Pablo, cit. (n. 10), p. 489.

${ }^{33}$ Memoria que el Ministro de Estado en el Departamento de Justicia. Culto e Instrucción Pública presenta al Congreso Nacional, año de 1842, en Documentos parlamentarios. Discursos de apertura en las sesiones del Congreso i memorias ministeriales correspondientes al pmer. quinquenio de la administración Bulnes 1842-1846 (Santiago, Imprenta del Ferrocarril, 1858), p. 25.

${ }^{34}$ Brangier, Víctor, El problema de la administración de justicia "lega" y "experta" en Chile siglo XIX. El valor heurístico de los expedientes judiciales, en Nuevo Mundos Mundos Nuevos (París, 2012), p. 2/6. [visible en internet: https://journals.openedition.org/nuevomundo/62756]

${ }^{35}$ BRANGIER, Víctor, Los acuerdos por sobre la ley. Ajustes entre motivaciones judiciales "legas" y el accionar de jueces letrados en la administración de justicia criminal: zona centro-sur de Chile, 1824-1875, en Palma, Daniel (ed.), Delincuentes, policías y justicias. América Latina, siglos XIX y XX (Santiago, Ediciones Universidad Alberto Hurtado, 2015), pp. 411-437.

${ }^{36}$ EnRíqueZ, Lucrecia, cit. (n. 23), pp. 645-670; sobre la judicatura local en el periodo tardocolonial, ver los artículos de CoBos, María Teresa, La institución del juez de campo en el reino de Chile durante el siglo XVIII, en REHJ., 5 (1980), pp. 85-165; y de ella misma y LORENZO, Santiago, Esquema de la administración de justicia en las áreas rurales chilenas, 1700-1786", en RDPUCV., 9 (1985), pp. 65-88. 
tendencias legalistas del periodo, como por ejemplo la persecución del delito de "torcida administración de justicia", habrían tenido un importante sello formativo e inclusive, paternalista. Esto es, en el sentido de que el Estado habría procurado educar y acompañar la acción del juez local, en un momento en que la justicia comenzaba a registrar reales transformaciones tendientes a su modernización, al alero de las leyes de organización judicial que fueron dotando de fisonomía propia a la judicatura ${ }^{37}$. Aun cuando estamos de acuerdo con la finalidad formativa de estas iniciativas, la existencia de los manuales también obedeció, según hemos dicho, al control político que se pretendía ejercer sobre estos jueces.

En la Memoria del año 1843 se dice que el texto ya estaría concluido, aunque se esperaría una visita judicial que detallara los abusos cometidos por subdelegados e inspectores, insumo que serviría para mejorar el documento: "El prontuario en que, según anuncié al Congreso el año pasado, han de recopilarse, con las explicaciones convenientes, todas las leyes y disposiciones que tiendan a suministrar a los jueces de menor cuantía la instrucción necesaria de sus deberes, se encuentra ya concluido. Grandes vacíos se advierten sin embargo en él, que no podrán llenarse sino en vista de los datos y observaciones que transmita la persona a quien ha de encargarse la visita judicial por toda la República. Con mejor inteligencia de los abusos, cuya extirpación convenga, se dará entonces la posible perfección a este pequeño manual' 38 .

La Memoria del año 1844 no contiene referencias explícitas al texto, pero sí da cuenta de la circulación entre alcaldes y subdelegados de "[...] modelos de procesos verbales y de sumarios por escrito, para evitar en algún modo la necesidad en que se veían los testigos, de recorrer grandes distancias para prestar sus declaraciones, y las dificultades consiguientes que se experimentaban en la averiguación de los delitos y de sus perpetradores" ${ }^{39}$. Esto demuestra que el recurso a la utilización de formularios y textos forenses, tan común en el siglo XIX ${ }^{40}$, se extendía a quienes aplicaban la ley.

Finalmente, la Memoria del año 1845, año en que se publicó el Manual, señala que: "Por lo pronto se ha creído mejorar la administración de justicia en esta parte, repartiendo a los Suddelegados e Inspectores instrucciones detalladas sobre sus deberes,

${ }^{37}$ Véase las primeras páginas del presente artículo.

${ }^{38}$ Memoria que el Ministro de Estado en el Departamento de Justicia. Culto e Instrucción Pública presenta al Congreso Nacional, año de 1843, en Documentos parlamentarios. Discursos de apertura en las sesiones del Congreso i memorias ministeriales correspondientes al pmer. quinquenio de la administración Bulnes 1842-1846 (Santiago, Imprenta del Ferrocarril, 1868), p. 140. La visita judicial que señala la fuente tiene su origen en la ley de 30 de noviembre de 1842 . Esta se concretó recién a partir del 21 de diciembre de 1847 y se prolongó hasta 1849 . Estuvo a cargo del ministro Antonio Varas. Para más detalle véase BrangIER, Víctor, Transacciones, cit. (n. 6), pp. 135 ss.

${ }^{39}$ Memoria que el Ministro de Estado en el Departamento de Justicia. Culto e Instrucción Pública presenta al Congreso Nacional, año de 1844, en Documentos parlamentarios. Discursos de apertura en las sesiones del Congreso i memorias ministeriales correspondientes al pmer. quinquenio de la administración Bulnes 1842-1846 (Santiago, Imprenta del Ferrocarril, 1868), p. 258.

${ }^{40} \mathrm{Al}$ respecto, véase SALVAT, Manuel, Los prontuarios jurídicos chilenos en la primera mitad del siglo XIX, en Biblioteca del Congreso Nacional, Homenaje a Guillermo Feliu Cruz (Santiago, Editorial Andrés Bello, 1973), passim, y del mismo autor, Sentido y forma de los prontuarios judiciales, en Revista de Derecho Procesal, 7 (Santiago, 1974), passim. Bravo, Bernardino, Derecho común y derecho propio en el Nuevo Mundo (Santiago, Editorial Jurídica de Chile, 1989), p. 329. 
y con esta mira se hizo al principio de este año y por cuenta del Gobierno una nueva edición de la instrucción de Subdelegados e Inspectores, trabajada por encargo de mi predecesor" ${ }^{\prime 1}$. Si bien se dice que es una "nueva edición", creemos que la alusión al texto trabajado en el gobierno de Joaquín Prieto es más bien a un proyecto que no habría visto la luz. Sostenemos aquello porque revisadas las Memorias de los años 1834, 1835, 1839, 1840 y 1841, nada se dice sobre el tema. Con todo, tenemos constancia de otro documento similar publicado en el año 1842, pero de alcance local, cuestión sobre la que volveremos más adelante.

La otra vía que nos permite afirmar que el texto del año 1845 es la primera edición del texto es el "Discurso del Presidente de la República en la apertura de las cámaras legislativas de 1845", donde se afirma que: "Se ha dado a luz una recopilación de las leyes relativas a la administración de justicia en los pleitos de menor cuantía, distribuyéndolas en el orden de materias para facilitar a los funcionarios que la ejercen [en] el desempeño de su cargo"42.

La publicación del Manual no constituyó de por sí una novedad en la cultura jurídica chilena de aquel entonces. Como adelantamos, existía ya en 1842 una publicación similar editada en la ciudad de La Serena, llamada "Instrucciones para los procedimientos de los Subdelegados e Inspectores" ${ }^{33}$, consistente en una compilación de leyes y formularios preparada al parecer por José Santiago Rodríguez, juez de letras de Coquimbo, y orientada a los jueces locales de aquella provincia. En ella se define el campo jurisdiccional de los “jueces de menor cuantía”, a partir de dos fuentes principales: el Reglamento de Administración de Justicia de 1824 y los decretos de 1837 conocidos como "Leyes marianas", que regularon una serie de materias judiciales, todas ellas encaminadas a encauzar la actividad del juez en el marco del proceso de construcción estatal durante los gobiernos de Prieto y Bulnes. Dicha actividad, de acuerdo a este instructivo, debía ajustarse a "lo literal de la ley", a fin de erradicar el arbitrio judicial y el estilo casuista que primó durante la vigencia del derecho indiano durante la monarquía ${ }^{44}$.

Para cerrar el tópico relativo a las ediciones, se asevera que, al ser una publicación ex i t o s a en su primer tiraje, fue re-editada por la Imprenta del Estado en 1852 , en 1853 por la Imprenta de la Sociedad, en 1860 por la Imprenta del Ferrocarril y en 1870 por la Imprenta de la República, todas con autoría anónima y publicadas en Santiago. Existe otra edición de 1877 preparada por Robustiano Vera, cuyo nombre es Manual para los jueces del distrito y de subdelegación, con un

${ }^{41}$ Memoria que el Ministro de Estado en el Departamento de Justicia. Culto e Instrucción Pública presenta al Congreso Nacional, año de 1845, en Documentos parlamentarios. Discursos de apertura en las sesiones del Congreso i memorias ministeriales correspondientes al pmer. quinquenio de la administración Bulnes 1842-1846 (Santiago, Imprenta del Ferrocarril, 1868), p. 381.

${ }^{42}$ Discurso del Presidente de la República en la apertura de las cámaras lejislativas de 1845 [Santiago, 1 de junio de 1845], en Documentos parlamentarios. Discursos de apertura en las sesiones del Congreso, i memorias ministeriales correspondientes al pmer. quinquenio de la administración Bulnes 1842-1846 (Santiago, Imprenta del Ferrocarril, 1868), p. 350.

${ }^{43}$ ANÓNIMO. Instrucciones para los procedimientos de los Subdelegados e Inspectores (La Serena, Imprenta del Colegio, 1842), en ArChivo NaCional Histórico, Fondo Ministerio de Justicia, 73.

${ }^{44} \mathrm{TAU}$, Víctor, Casuismo y sistema. Indagación histórica sobre el espiritu del derecho indiano (Buenos Aires, Instituto de Investigaciones de Historia del Derecho, 1992), pp. 39-227. 
apéndice para los subdelegados e inspectores, y en la que pensamos se mantiene el espíritu de los primeros manuales publicados en la década de los cuarenta ${ }^{45}$. La diferencia ahora, se marcaría bajo el signo de la Ley de Organización y Atribuciones de los Tribunales de 1875, que incorporó la figura de los jueces de distrito y de subdelegación, en reemplazo de subdelegados en inspectores. A estos últimos y en razón de la experiencia anterior, se les deslindaron las funciones judiciales de las administrativas. El mensaje presidencial que acompañó al Congreso el proyecto de Ley de 1875 es elocuente: "Los jueces de subdelegación y los de distrito desempeñarán estos empleos como cargos concejiles y serán nombrados para periodos bianuales por los gobernadores de departamento, a propuesta en terna de los jueces de letras. En homenaje a los preceptos de la Constitución Política, el proyecto hace extensiva a estos jueces la separación de funciones judiciales y de las funciones administrativas. De desear habría sido que se llevara más lejos la reforma de lo existente, gravoso en verdad para los que ejercen estas funciones, poco satisfactorio para los que tienen que ocurrir ante ellos. Para eso, empero, habría sido menester crear gran número de tribunales remunerados; $y$ las rentas públicas no han alcanzado todavía a tal grado de prosperidad que les permita soportar cómodamente ese nuevo y considerable gravamen" ${ }^{46}$.

\section{El Manual como manifestación de la literatura jurídica práctica del siglo XIX}

De acuerdo con Bravo y Salvat, estos textos se inscriben dentro de una corriente de literatura jurídica práctica que abundó durante todo el siglo XIX, y cuyo origen se remonta a la centuria anterior. En este punto cabe evocar las "instrucciones" elaboradas para la adecuada substanciación de los juicios criminales, dirigidas a los corregidores y jueces subordinados de las villas y partidos del entonces reino de Chile. La primera de José Perfecto de Salas, de 25 de agosto de 1757, y la segunda de Ambrosio Cerdán y Pontero, de 16 de marzo de $1778^{47}$. Incluso más, en perspectiva de larga duración, toda esta vertiente puede enquistarse en la literatura normativa práctica de la época indiana. Últimamente y para el campo de la teología moral de los siglos XVI y XVII, Duve la ha denominado "literatura normativa pragmática", definiéndola como "[...] written texts used by practitioners in an immediate way to access the relevant normative knowledge required to produce a normative statement related to the legitimacy of human action" ${ }^{48}$.

${ }^{45}$ Bilot, Pauline; Whipple, Pablo, cit. (n. 10), p. 489. Estos autores señalan una edición de 1853 por Imprenta de la Sociedad, reconocen las otras que hemos citado y no dan noticias del texto del año 1877.

${ }^{46}$ Mensaje con que el Presidente de la República acompañó al Congreso Nacional el proyecto de Lei de Organizacion i Atribuciones de los Tribunales, 3 de junio de 1874, citado en BaLlesteros, Manuel, La Lei de Organización i Atribuciones de los Tribunales de Chile (Santiago, Imprenta Nacional, 1890), I, p. 2.

${ }^{47}$ Dougnac, Antonio, Los principios clásicos del procedimiento y la palabra hablada en el sistema jurídico indiano. El estilo de Chile, en REHJ., 28 (2016), pp. 455-456.

${ }^{48}$ Textos escritos utilizados por prácticos como manera inmediata para acceder al conocimiento normativo relevante requerido para producir una declaración normativa relacionada con la legitimidad de la acción humana [traducción libre de los autores]. Duve, Thomas, Pragmatic Normative Literature and the Production of Normative Knowledge in the Early Modern Iberian Empires in the 16th-17th Centuries, en Max Planck Institute for European 
Los primeros dos autores arriba citados sostienen la existencia de los denominados prontuarios judiciales, que no solo apuntaron al tipo de judicatura que hemos señalado aquí, sino también a los bachilleres en derecho y abogados que se veían en la necesidad de acudir a un manual impreso, para evitarse la transcripción de manuscritos y, sobre todo, facilitar la circulación de nuevas leyes que surgían en el marco de configuración de la república ${ }^{49}$. Es decir, una literatura jurídica práctica que tenía un público diverso (legos y letrados) y un contenido distinto (síntesis de materias jurídicas y reunión de leyes vigentes).

A juicio de Salvat, los prontuarios judiciales publicados entre 1820 y 1850 tuvieron un sentido y una finalidad múltiple, de acuerdo a su naturaleza. Entre los más comunes, se encuentra la guía de tramitación de los juicios para abogados y jueces, en un contexto en el que la norma procesal se cambiaba rápidamente, incluyéndose también las nuevas leyes dictadas sobre diversas materias. También encontramos los modelos de redacción, en el que destacan los testamentos y contratos. Adicionalmente, se incluye la función normativa para cargos, como los que hemos descrito, pero también eclesiásticos como los párrocos. Finalmente, se ubican aquellos manuales de naturaleza más general que constituyen resúmenes del orden jurídico vigente, a partir de las disposiciones legales que lo integraban y el parecer de la doctrina de la época ${ }^{50}$. Dichos prontuarios, en definitiva, fueron capitales en la superación de algunos problemas ligados a conciliar la norma preexistente con las nuevas disposiciones que se fueron dictando, pues facilitaron la consulta de leyes aplicables, promovieron la estandarización de los procedimientos, a través del uso de los formularios, herramientas útiles en la redacción de escritos, providencias y contratos ${ }^{51}$.

\section{El Manual: texto y contexto}

Como hemos adelantado, el sentido de la fuente que aquí se comenta podría reflejar una intención más profunda, la que se advierte de antemano en su composición. Un breve recorrido por sus páginas da cuenta de que se trata de un extracto prácticamente literal de la Ley de arreglo al Régimen Interior, promulgada en Chile durante 1844. En términos generales, dicha ley promovía la organización administrativa del país relativa a los funcionarios de gobierno de las provincias, de los departamentos, de las subdelegaciones y los distritos. La historiografía ha sido bastante crítica respecto a la aplicación de esta normativa, juzgándola como un verdadero fracaso. Sin embargo, lo interesante es conocer el trasfondo de su creación, los temas que preocupaban al poder legislativo y sobre todo, la mirada que surgía desde Santiago respecto a las prácticas de la judicatura local.

Legal History Research Paper Series No. 2019-19, p. 17. [visible en internet: https://ssrn.com/ abstract $=3447223$.

${ }^{49}$ Salvat, Manuel, Los prontuarios jurídicos chilenos en la primera mitad del siglo XIX, en Biblioteca del Congreso Nacional, Homenaje a Guillermo Feliu Cruz (Santiago, Editorial Andrés Bello, 1973), pp. 905-906; Bravo, Bernardino, Derecho, derecho común, cit. (n. 40), pp. 343-344.

${ }^{50}$ SalVat, Manuel, Los prontuarios, cit. (n. 49), p. 909.

${ }^{51}$ Salvat, Manuel, Sentido y forma de los prontuarios, cit. (n. 40), p. 71. 
Entre los temas discutidos en 1842 por el Senado en el marco de la preparación de esta norma se encuentra el deseo de terminar con las "atribuciones judiciales" de los "jueces de menor cuantía", las que muchas veces se practicaban "de manera vejatoria", ocasionando "grave perjuicio, de los litigantes y del público" 52 . Por este motivo, consideraban que la visita judicial -otra práctica ligada a este tipo de control propuesto por la referida ley-, sugería que los jueces visitadores pudieran destituir a inspectores y subdelegados a partir de la formación de sumarios, considerando su mala conducta, el abandono de deberes, el desorden administrativo, no solo respecto a jueces locales, sino también a sus auxiliares (procuradores, escribanos, receptores, etc.).

Otra de las preocupaciones en este periodo es la necesidad de contar con algún estipendio o sueldo para intendentes y gobernadores, dejando fuera de preocupación a subdelegados e inspectores. Esta preocupación se basa en que mientras no exista cómo recompensar estos servicios, se prolongaría la escasez de personas aptas para estos cargos, los que generalmente recaían en los militares de ejército, cuestionándose que la administración política de la república se convirtiese en un régi m e n m il i ta r. La cuestión de la escasez era extensiva para el caso de subdelegados e inspectores, los que muchas veces eran referidos como cargos que no se podían cubrir con facilidad, recayendo por lo general en los mismos vecinos o moradores d e c e n t e s de cada pueblo. De tal modo, los vicios y abusos cometidos por la justicia local se volvían un factor estructural, al impedirse la rotación del cargo con otros ciudadanos. La ley estipulaba que tanto en el cargo de gobernador, subdelegado e inspector, se debía ejercer con "capacidad, honradez y patriotismo", y que el acto de denegarse a servir en estos cargos concejiles -ejercidos ad honorem - significaba una multa de ciento cincuenta pesos en el caso de los subdelegados y de cincuenta en el caso de inspectores ${ }^{53}$.

Entre otras recomendaciones de la ley, se encuentra el hecho de que los subdelegados e inspectores otorgasen recibo de los dineros que cobraran en el marco de sus atribuciones, así como que pudieran ser reconvenidos por sus observantes superiores cuando se observaran sus excesos sobre lo notoriamente legal o si hubieran traspasado sus facultades. Como puede apreciarse, las preocupaciones no solamente abordaron el tema de la observancia del derecho en los procedimientos ejecutados por la judicatura local, sino también los reiterados y típicos excesos y vicios ya dichamente característicos de un cargo cuyo funcionamiento, por tradición o negligencia, se amparaba en la discrecionalidad. En otras palabras, se hacía énfasis en que el desempeño de estos jueces debía -a partir de esta instrucción-, fundarse en consonancia con la probidad deseable de esta investidura.

Dichos elementos, discutidos en el marco de la Ley precitada, se tornan en presupuestos basales en la formulación del denominado Manual, cuyo extracto de la ley de 1844 configura una parte sustancial de su contenido. Ya hemos indicado que en la propia publicación con la que contamos para este análisis (de 1860), se explica que los tres primeros capítulos corresponden a extractos más o menos

\footnotetext{
${ }^{52}$ Letelier, Valentín (comp.), Sesiones de los cuerpos lejislativos de la República de Chile (1811 a 1845) (Santiago, Imprenta Cervantes, 1906), XXI, anexo 70, 17 de agosto de 1842, pp. 62-63.

${ }^{53}$ Letelier, Valentín, cit. (n. 52), XXXII, anexo 311, 9 de septiembre de 1843, pp. 438-442.
} 
literales de la ley de régimen interior de 1844. El I capítulo de ellos caracteriza el concepto administrativo que se tenía de los subdelegados e inspectores en aquella ley (Quiénes pueden o no ser...Quiénes los nombran...Causas para exonerarse de esos cargos...etc.), mientras que el II y III capítulo, abordan las facultades y deberes de los subdelegados considerados como agentes del "Supremo Poder Ejecutivo". Rasgo que, como ya hemos dicho, refleja la dependencia de estos oficios respecto del gobierno y no de la judicatura. Otro atributo ya expuesto supra, asociados a la ley de 1844, es el anhelo de formular un poder centralizado y extensivo del Ejecutivo sobre todas las provincias, lo que la historiografía calificó en su momento de estrepitoso fracaso, ya que esta orgánica nunca pudo disolver del todo la relativa autonomía y resistencia de los viejos cuadros y poderes locales ${ }^{54}$.

En relación a los capítulos restantes, constituyen una elaboración propia para este Manual y corresponden a los apartados que van desde el número IV al IX. En el capítulo IV, se discute la jurisdicción de los subdelegados e inspectores en pleitos civiles y el modo de proceder en ellos. Al respecto, es relevante la definición de las cuantías en las que estos oficios podían ocurrir, lo que se esbozó primeramente en el apartado anterior. Tratándose de los inspectores, aquellas demandas civiles de menos de doce pesos, y en las que la demanda sobrepasara los doce pesos pero no los cuarenta, la parte agraviada podía acudir ante el subdelegado para su apelación. Por su parte, los subdelegados intervenían en causas entre los cuarenta y los ciento cincuenta pesos, las que siendo sobrepasadas podían apelarse ante " $\mathrm{el}$ Subdelegado de la subdelegación siguiente en el orden con que estén numeradas las subdelegaciones del departamento", cuestión que-en términos prácticos-podía ser objeto de largos traslados por parte del agraviado, incidiendo en la disolución de la demanda o en la búsqueda de un arreglo extrajudicial.

Además de estas definiciones, el capítulo abunda en la descripción de procedimientos (citación de las partes, testigos, etc.), y estilo de dictación de sentencias. El punto 52 sugiere que los subdelegados llamasen un letrado para consultar en aquellas causas que se creyera conveniente; mientras que el punto 59 advierte que la instrucción ha considerado "aquellas nociones que consideramos más necesarias", ya que sería demasiado largo e inútil entrar todas las diferentes clases de juicios y sus pormenores.

En los capítulos V y VI se abordan los delitos leves y la forma de proceder en ellos, respectivamente. La distinción entre un delito leve y uno grave es de suma importancia -dice el texto- para que los jueces de menor cuantía entiendan los límites de su jurisdicción en lo criminal. Sin embargo, este documento sostiene que no es posible hacer una clasificación completa, atendiéndose a sus principios generales contenidos en la legislación vigente. Un rasgo llamativo de la clasificación ante citada es que se entreveran nociones nuevas con algunas más provenientes del orden jurídico indiano - por ejemplo, con arreglo a la Novísima Recopilación-como las injurias graves proferidas de palabra (gafo, leproso, sodomético

\footnotetext{
${ }^{54}$ Barros Arana, Diego, Un decenio de la historia de Chile (1841-1851) (Santiago, Instituto de Historia, Pontificia Universidad Católica de Chile, 2003), I, pp. 201-202; UrzúA, Germán, Evolución de la administración pública chilena (1818-1968) (Santiago, Editorial Jurídica de Chile, 1970), pp. 70-71.
} 
[sic], cornudo, traidor, hereje, puta, etc.) de aquellas livianas o menores; las que se entiende por graves si se hacen por escrito impreso y se echan "en las casas de los grandes señores" (libelo famoso). Estos elementos caracterizan una serie de dimensiones legales que están mutando profundamente en el Chile de mediados del siglo XIX, de acuerdo no solo al cambio jurídico sino a la tipificación de conflictos, antes poco comunes.

Por su parte, el capítulo VI informa la forma de redactar el proceso verbal, cuyo modelo habría sido aprobado por el Poder Ejecutivo y la Corte Suprema en 1832, indicándose como ejemplo un caso de un hurto simple cuya relación de hechos y forma de sumariar la causa representan un expediente criminal típico del periodo ${ }^{55}$.

En el capítulo VII, el Manual señala el modo de proceder en los delitos graves, indicándose que si estos se cometiesen en los pueblos donde residan intendentes, gobernadores o alcaldes, los jueces de menor cuantía remitirán su acción a la aprehensión de delincuentes, con relación escrita de por medio, y obligarán a los testigos a comparecer ante el juez que conozca la causa. Si, por el contrario, los delitos se cometieran a distancia de dichos pueblos, será el subdelegado o inspector el que levante el auto cabeza de proceso. En este acápite se incluyen los modelos de redacción, incluyendo -además del auto cabeza de proceso- el reconocimiento de muertos o heridos, las compulsas de testigos, la forma de redactar las confesiones, los nombramientos de curadores, el careo entre partes, la ratificación de testigos y los autos de remisión. Conviene señalar que muchas de estas formas protocolares de ilustrar el procedimiento tampoco constituyeron elementos innovadores. De acuerdo con lo sostenido por Lucrecia Enríquez, ya en el marco de las instrucciones a los jueces diputados, que datan de 1786, existían lineamientos claros sobre cómo formalizar las causas en las que podían conocer estos "jueces auxiliares" ". Igualmente, las instrucciones de José Perfecto de Salas y de Ambrosio Cerdán y Pontero, ya descritas.

El capítulo VIII trata las causas por heridas y uso de armas prohibidas, en donde se recomienda al subdelegado tener en cuenta el "Senado Consulto de veinte de marzo de 1824", donde se prohíbe la carga de ciertas armas, y la tipificación de causas por heridas. Sin embargo, la instrucción recordó que -de acuerdo al artículo 9 de esta ley- al no ser los inspectores jueces competentes para juzgar este tipo de causas, debían remitirse a formar sumario en caso de muerte o lesiones graves.

Finalmente, el capítulo IX regulas las implicancias y recusaciones, describiendo las inhabilidades legales propias de ambos institutos, con sus respectivas adiciones sobre la separación de un juez en caso de producirse algunas de las causas especificadas. Se incluye un breve suplemento, en donde se agregan recomendaciones varias sobre otras materias, como las subrogaciones. Asimismo, la formación de

55 Por razones de extensión no podemos detenernos en las raíces indianas de este procedimiento criminal. Sobre el punto puede verse el trabajo de Dougnac, Antonio, Apuntes sobre el tránsito del procedimiento penal indiano al patrio (1810-1842), en Homenaje a los profesores Alamiro de Avila M., Benjamín Cid Q. y Hugo Hanish E. (Santiago, Ediciones Universidad del Desarrollo, 2005), pp. 165-273.

${ }^{56}$ EnRíqueZ, Lucrecia, cit. (n. 23), p. 657. Véase también la nota 47. 
causas por vejaciones, dilaciones, torcida administración de justicia y otros crímenes cometidos por estas judicaturas, con particular atención al de denegación de justicia, que implicaba la suspensión o privación del oficio, y las multas al respecto.

Como se ha indicado anteriormente, la publicación de estos textos habría sido exitosa, al menos en su primer tiraje, lo que significó su re-edición a lo largo del siglo XIX en varias ocasiones. Pero, en estricto rigor, ¿qué significado tuvo dicho éxito? ¿Se refiere al éxito de su distribución o a la acogida del Manual por los diversos subdelegados e inspectores? Respecto a su distribución, no tenemos antecedentes sobre el tiraje de cada edición, pero de acuerdo con lo sostenido por Pauline Bilot, el ministro Antonio Varas -sucesor de Montt en la cartera de justicia-, habría mencionado la necesidad de seguir difundiéndolos y editándolos, lo que revela una distribución exitosa de su primera versión, asunto que se corrobora con lo expresado al respecto en las memorias ministeriales ya analizadas. No obstante, respecto a su acogida, la duda permanece, ya que no se cuenta con un informe detallado de su repartición a lo largo y ancho de Chile.

Por otra parte, sí es posible planear la asimilación o puesta en práctica de algunos de los principios del Manual, sobre todo si cuestionamos el conocimiento de dicho texto en todos los lugares del país, lo que va más allá de la completa y exitosa distribución de sus primeras ediciones.

Un antecedente clarificador respecto a este último punto, lo brinda la visita judicial practicada por el juez de letras Pedro Matus en diciembre de 1861 -más de quince años después de la primera edición del texto-al departamento de Arauco (provincia de Concepción), oportunidad en la que observó que subdelegados e inspectores de aquella jurisdicción conocían en asuntos civiles y criminales que no formaban parte de sus competencias. Ello había creado condiciones para exhibir situaciones vejatorias por parte de estos jueces, cuyas funciones se ejercían sin nombramientos previos, ni la investidura en propiedad por parte de autoridades competentes. La circular emitida por Matus se dirigió, entonces, a recordar algunas prescripciones a los distintos subdelegados del departamento, en diecisiete puntos, los que recuerdan en gran medida a los tópicos tratados en el opúsculo. En el tercer punto, el letrado es explícito en su llamada a recordar la importancia de limitar la jurisdicción de estos jueces a pleitos de cuantía mínima o menor, "sobre lo cual deberán estarse a lo prevenido en el Manual de Instrucción para Subdelegados e Inspectores que deberá entregárseles por la autoridad a quien corresponde hacer sus nombramientos" 57 . En vista de que no pocos jueces locales practicaban sus oficios sin nombramientos oficiales, el conocimiento del documento podría haber sido - al menos- deficiente desde el punto de vista de su asimilación, sobre todo considerándose que una buena parte de estos oficios eran ejercidos por sujetos semi-analfabetos, lo que también queda expuesto en la ausencia de libros o cuadernos copiadores de los oficios, asunto que también fue objetado de forma reiterada en las visitas judiciales practicadas por jueces letrados, a mediados del siglo XIX. Sobre la ignorancia de quienes ejercían estos cargos, asunto recurrente

${ }^{57}$ Circular de Pedro Matus a los subdelegados de Arauco respecto a sus atribuciones (20 de diciembre de 1861), en Archivo Nacional Histórico, Fondo Ministerio de Justicia, 56. 
en la época, cabe mostrar lo dicho en la Memoria de 1847. También, este testimonio develaría un aparente fracaso del Manual: "Se ha procurado remediar en cuanto ha sido posible la ignorancia absoluta del común de estos funcionarios, fecundo y ordinario origen de sus desaciertos, distribuyéndoles en todas las provincias libros que les enseñen sus obligaciones; pero este bien es ilusorio respecto de aquellos a quienes falta el tiempo o más probablemente la voluntad de estudiarlas" ${ }^{58}$.

Una pregunta latente que queda por formular y que podría ser objeto de otra disquisición más profunda, es si acaso la formulación de estos libros jurídicos, junto a otras medidas practicadas en el periodo como la visita judicial, podrían constituir políticas efectivamente innovadoras, desde la intención de promover desde lo práctico una observancia legal más apegada a la forma m o d e r $\mathrm{n}$ a de interpretar la función jurisdiccional del Estado, o bien, una política regresiva en el sentido de buscar consolidar una práctica judicial inveterada, y que por muchos motivos, el Estado no podía reformar de manera taxativa, ya sea por falta de recursos económicos, humanos o culturales ${ }^{59}$. En ese sentido, el desafío de la reforma judicial y de la instauración de una justicia letrada en Chile, tuvo que fluctuar entre utopías organizativas y entre resoluciones pragmáticas, cuyos matices constituyen un proceso no lineal y muchas veces digresivo, en el contexto del proceso de construcción estatal del Chile decimonónico.

\section{SíNTESIS Y CONCLUSIONES}

La organización de la judicatura en la época que va desde 1817 hasta 1875 se estructuró sobre ideas e institutos provenientes de la época indiana y de innovaciones propias del periodo republicano. En materia de tribunales, esto se tradujo en la incorporación de una Corte Suprema como tribunal superior, una Corte de Apelaciones localizada en Santiago, a la que se agregaron otras fundadas a lo largo del siglo XIX, y una red de tribunales inferiores, a cargo de jueces de letras, alcaldes, subdelegados e inspectores. Salvo los jueces de letras, los restantes magistrados en quienes, además, recaía la toda justicia local, eran todos legos.

A medida que avanzaba el proceso de construcción estatal de la república y el legalismo inspirado en la codificación y el constitucionalismo, el desconocimiento de la ley por parte de estos agentes de la justicia era un problema que debía erradicarse. Su nula preparación y, a menudo, la falta de comprensión que suponían estas innovaciones, fueron factores que propiciaron que muchas de sus decisiones se fundaran más en las prácticas y en usos locales que en literalidad de la ley. Ello llevó al ejecutivo a proponer la edición de textos que instruyeran a estos jueces, para así resolver paliativamente este problema, lo que justifica la existencia del Manual.

Como hemos visto, la dictación de este libro no significó una auténtica

\footnotetext{
${ }^{58}$ Memoria que el Ministro de Estado en el Departamento de Justicia. Culto e Instrucción Pública presenta al Congreso Nacional, año de 1847 (Santiago, Imprenta de los Tribunales, 1847), p. 56.

${ }^{59}$ Brangier, Víctor; Díaz, Alberto; Morong, Germán, Acusaciones contra jueces legos ante jueces de letras: uso social del avance de la justicia letrada. Zona centro-sur de Chile, 1824-1875, en História Unisinos, 22/1 (São Leopoldo, 2018), pp. 75-87.
} 
solución al problema. En efecto, las propias memorias ministeriales confirman la persistencia del mismo, toda vez que insisten sobre el asunto. No obstante, creemos que se trata de un tópico que con las fuentes examinadas no puede dilucidarse del todo. Adicionalmente, esta iniciativa debe mirarse como un medio de control hacia estas judicaturas, medida enquistada en un conjunto mayor de acciones, tales como las visitas judiciales, las normas que castigaban el delito de denegación de justicia y demás.

De acuerdo con la literatura consultada, este opúsculo forma parte de una corriente de textos jurídicos prácticos, que sirvieron a quienes operaban el derecho de la época. La novedad en este punto radica en que se trata de una publicación de origen oficial destinado a quienes debían declarar lo justo para el caso concreto. Asimismo, su contenido es evocativo de la normativa empleada en la época indiana y de las leyes dictadas durante el siglo XIX en las materias que este regula. Creemos que el breve examen del texto deja abierta una serie de interrogantes, que pueden servir de guía para estudios ulteriores. Así, ¿cuál fue la eficacia del texto para consolidar el legalismo en la resolución de conflictos?, ¿quién o quiénes fueron sus autores?, ¿hubo otras intenciones más profundas que explican la promoción de este texto por parte del poder ejecutivo? ¿coexistió con textos similares, pero de alcance local? En suma, las preguntas ya vertidas son el acicate para proseguir explorando el mundo cultural y jurídico que rodeó al Manual o instrucción para los subdelegados e inspectores en Chile.

\section{Bibliografía}

Fuentes

Anónimo, Manual o instruccion para los subdelegados e inspectores en Chile. (3a ed., Santiago, Imprenta del Ferrocarril, 1860). [visible en internet: https://archive. org/details/b28749807/]

ANÓNImO. Instrucciones para los procedimientos de los Subdelegados e Inspectores (La Serena, Imprenta del Colegio, 1842), en Archivo Nacional Histórico, Fondo Ministerio de Justicia, 73.

Anguita, Ricardo, Leyes promulgadas en Chile desde 1810 hasta el $1^{\circ}$. De junio de 1912 (Santiago, Imprenta, Litografía i Encuadernación Barcelona, 1912), I-II.

Circular de Pedro Matus a los subdelegados de Arauco respecto a sus atribuciones (20 de diciembre de 1861), en Archivo Nacional Histórico, Fondo Ministerio de Justicia, 56.

Discurso del Presidente de la República en la apertura de las cámaras lejislativas de 1845 [Santiago, 1 de junio de 1845], en Documentos parlamentarios. Discursos de apertura en las sesiones del Congreso, i memorias ministeriales correspondientes al pmer. quinquenio de la administración Bulnes 1842-1846 (Santiago: Imprenta del Ferrocarril, 1868).

Letelier, Valentín (comp.), Sesiones de los cuerpos lejislativos de la República de Chile (1811 a 1845) (Santiago, Imprenta Cervantes, 1906), XXI y XXXIII.

Memoria que el Ministro de Estado en el Departamento de Justicia. Culto e Instrucción Pública presenta al Congreso Nacional, año de 1842 en Documentos parlamentarios. Discursos de apertura en las sesiones del Congreso i memorias ministeriales corres- 
pondientes al pmer. quinquenio de la administración Bulnes 1842-1846 (Santiago, Imprenta del Ferrocarril, 1858).

Memoria que el Ministro de Estado en el Departamento de Justicia. Culto e Instrucción Pública presenta al Congreso Nacional, año de 1843 en Documentos parlamentarios. Discursos de apertura en las sesiones del Congreso i memorias ministeriales correspondientes al pmer. quinquenio de la administración Bulnes 1842-1846 (Santiago, Imprenta del Ferrocarril, 1858).

Memoria que el Ministro de Estado en el Departamento de Justicia. Culto e Instrucción Pública presenta al Congreso Nacional, año de 1844 en Documentos parlamentarios. Discursos de apertura en las sesiones del Congreso $i$ memorias ministeriales correspondientes al pmer. quinquenio de la administración Bulnes 1842-1846 (Santiago, Imprenta del Ferrocarril, 1858).

Memoria que el Ministro de Estado en el Departamento de Justicia. Culto e Instrucción Pública presenta al Congreso Nacional, año de 1845 en Documentos parlamentarios. Discursos de apertura en las sesiones del Congreso $i$ memorias ministeriales correspondientes al pmer. quinquenio de la administración Bulnes 1842-1846 (Santiago, Imprenta del Ferrocarril, 1858).

Memoria que el Ministro de Estado en el Departamento de Justicia. Culto e Instrucción Pública presenta al Congreso Nacional, año de 1847 (Santiago, Imprenta de los Tribunales, 1847).

Mensaje con que el Presidente de la República acompañó al Congreso Nacional el proyecto de Lei de Organizacion i Atribuciones de los Tribunales, 3 de junio de 1874, citado en Ballesteros, Manuel, La Lei de Organización i Atribuciones de los Tribunales de Chile (Santiago, Imprenta Nacional, 1890).

Valencia, Luis, Anales de la República (2a ed., Santiago, 1986), I.

Literatura

BARRIENTOS, Javier, Regimenes de excepción y recursos de protección ante la jurisprudencia chilena, Anexo II-, en PEÑA, Carlos (ed.), Práctica constitucional y derechos fundamentales (Santiago, Corporación Nacional de Reparación y Reconciliación, 1996), pp. 353-423.

—La Real Audiencia de Santiago de Chile (1605-1817). La institución y sus hombres (Madrid, Fundación Histórica Tavera, 2000).

Barros Arana, Diego, Un decenio de la historia de Chile (1841-1851) (Santiago, Instituto de Historia, Pontificia Universidad Católica de Chile, 2003), I.

Bilot, Pauline, Construyendo un esquema de la administración de justicia: fuentes, métodos y resultados. Chile, siglo XIX, en Revista Historia y Justicia 1, (Santiago, 2013), pp. 1-27. [visible en internet: http://revista.historiayjusticia.org/dossier/ justicia-control-y-territorio/construyendo- un-esquema-de-la-administracionde-justicia-fuentes-metodo-y-resultados-chile-siglo-xix/].

Bilot, Pauline; Whipple, Pablo, Los desafios de la justicia republicana. Profesionalización e independencia de la judicatura en Chile y Perú durante el siglo XIX, en DE FraNCESCO, Antonino; Mascilli Migliorini, Luigi; Nocera, Raffaele (coords.), Entre Mediterráneo y Atlántico. Circulaciones, conexiones, miradas, 1756-1867 (Santiago, Fondo de Cultura Económica, 2014), pp. 477-500.

Brahm, Enrique, ¿Jurisprudencia creativa? La Corte Suprema de Justicia 1841-1860, en $R C h H D ., 16$ (Santiago, 1990), pp. 555-566. 
Brangier, Víctor, Transacciones entre ley y prácticas judiciales locales en tiempos de codificación. El caso de la Visita Judicial Nacional. Chile, 1848-1849, en Revista SudHistoria, 5 (Valdivia, 2012), pp. 124-151.

- El problema de la administración de justicia "lega" y "experta" en Chile siglo XIX. El valor heuristico de los expedientes judiciales, en Nuevo Mundos Mundos Nuevos (2012), sin número de páginas [visible en internet: https://journals.openedition. org/nuevomundo/62756].

-Los acuerdos por sobre la ley. Ajustes entre motivaciones judiciales "legas" y el accionar de jueces letrados en la administración de justicia criminal: zona centro-sur de Chile, 1824-1875 en Palma, Daniel (ed.), Delincuentes, policías y justicias. América Latina, siglos XIX y XX (Santiago, Ediciones Universidad Alberto Hurtado, 2015), pp. 411-437.

- Saber hacer y decir en justicia. Culturas jurídico judiciales en la zona centro-sur de Chile (1824-1875) (Rosario, Prohistoria, 2019).

Brangier, Víctor; Díaz, Alberto; Morong, Germán, Acusaciones contra jueces legos ante jueces de Letras: uso social del avance de la justicia letrada. Zona centro-sur de Chile, 1824-1875, en História Unisinos, 22/1 (São Leopoldo, 2018), pp. 75-87.

Bravo, Bernardino, Judicatura e institucionalidad en Chile (1776-1876): del absolutismo ilustrado al liberalismo parlamentario, en REHJ., 1 (Valparaíso, 1976), pp. 61-87.

-Derecho común y derecho propio en el Nuevo Mundo (Santiago, Editorial Jurídica de Chile, 1989).

-Arbitrio judicial y legalismo. El juez frente al derecho antes y después de la codificación en Europa e Iberoamérica, en ÉL MISMO, El juez entre el derecho y la ley, en el mundo hispánico. Del Estado de Derecho al derecho del Estado (siglos XVI a XXI) (Santiago, LexisNexis, 2006), pp. 361-375.

Cobos, María Teresa, La institución del juez de campo en el reino de Chile durante el siglo XVIII, en REHJ., 5 (1980), pp. 85-165.

Cobos, María Teresa; Lorenzo, Santiago, Esquema de la administración de justicia en las áreas rurales chilenas, 1700-1786", en RDPUCV., 9 (1985), pp. 65-88.

Corva, María Angélica La administración de justicia en la provincia de Buenos Aires, 1853-1881 (Tesis de posgrado. Universidad Nacional de La Plata. Facultad de Humanidades y Ciencias de la Educación, 2013). [visible en internet: http://www.memoria.fahce.unlp.edu.ar/tesis/te.878/te.878.pdf]

Dougnac, Antonio, Manual de historia del derecho indiano (México, MacGraw-Hill, 1998).

- Apuntes sobre el tránsito del procedimiento penal indiano al patrio (1810-1842), en Homenaje a los profesores Alamiro de Avila M., Benjamin Cid Q. y Hugo Hanish E. (Santiago, Ediciones Universidad del Desarrollo, 2005), pp. 165-273.

-Los principios clásicos del procedimiento y la palabra hablada en el sistema jurídico indiano. El estilo de Chile, en REHJ., 28 (2016), pp. 425-490.

Dougnac, Antonio; Cerón, Roberto, Una silueta de la judicatura chilena en el siglo $X I X$, en BAChH., 125 (Santiago, 2016), pp. 7-82.

Duve, Thomas, Pragmatic Normative Literature and the Production of Normative Knowledge in the Early Modern Iberian Empires in the 16th - 17th Centuries, en Max Planck Institute for European Legal History Research Paper Series No. 2019-19, pp. 1-32. [visible en internet: https://ssrn.com/abstract=3447223].

ENRÍQUeZ, Lucrecia, Los jueces diputados y los distritos judiciales borbónicos en Chile (1786-1818), en RChD., 43/2, (Santiago, 2016), pp. 643-668. 
FigueroA, María Angélica, La codificación civil chilena y la estructuración de un sistema jurídico legalista, en Congreso Internacional Andrés Bello y el Derecho (Santiago, Editorial Jurídica de Chile, 1981), pp. 77-104.

GuZMÁn Brito, Alejandro, La codificación civil en Iberoamérica (Santiago, Editorial Jurídica de Chile, 2000).

LORENTE, Marta, Reducción de la justicia, emergencia de la administración (España, 1810-1870). Una reflexión iushistori[o]gráfica, en RChHD., 22 (Santiago, 2010), I, pp. 333-340.

Navarro, Enrique, La Judicatura chilena del absolutismo ilustrado al Estado constitucional. De la Real Audiencia a la Corte de Apelaciones de Santiago (Memoria de Prueba para optar al Grado de Licenciado en Ciencias Jurídicas, Santiago, Facultad de Ciencias Jurídicas y Sociales de la Universidad de Chile, 1988).

PALma, Daniel, Los jueces del orden. Estructura y funciones de la justicia bajo dos regímenes autoritarios: Buenos Aires y Chile, 1829-1852, en Pinto, Julio; Palma, Daniel; Donoso, Karen; Pizarro, Roberto, El orden y el bajo pueblo. Los regimenes de Portales y Rosas frente al mundo popular, 1829-1852 (Santiago, LOM Ediciones, 2015), pp. 61-104.

Real Academia Española, Diccionario de la lengua castellana por la Real Academia Española. Novena edición (Madrid, Imprenta de D. Francisco María Fernández, 1843). [visible en internet http://ntlle.rae.es/ntlle/SrvltGUIMenuNtlle? $\mathrm{cmd}=\mathrm{L}$ ema\&sec=1.1.0.0.0.]

SALVAT, Manuel, Los prontuarios jurídicos chilenos en la primera mitad del siglo XIX, en Biblioteca del Congreso Nacional, Homenaje a Guillermo Feliú Cruz (Santiago, Editorial Andrés Bello, 1973), pp. 905-917.

— Sentido y forma de los prontuarios judiciales, en Revista de Derecho Procesal, 7 (1974), pp. 69-73.

Stabili, María Rosaria, Jueces y justicia en el Chile liberal, en Carmagnani, Marcello (coord.), Constitucionalismo y orden liberal. América Latina, 1850-1920 (Roma, Otto Editore, 2000), pp. 227-258.

TAU, Víctor, La administración de justicia en las provincias argentinas (1820-1853). Planteo preliminar para su estudio, en Revista de Historia del Derecho, 1 (Buenos Aires, 1973), pp. 205-249.

- Casuismo y sistema. Indagación histórica sobre el espiritu del derecho indiano (Buenos Aires, Instituto de Investigaciones de Historia del Derecho, 1992).

TISI, Ricardo, Regulación de la judicatura chilena entre 1810 y 1875 (Memoria de Prueba para optar al Grado de Licenciado en Ciencias Jurídicas, Santiago, Facultad de Ciencias Jurídicas y Sociales de la Universidad de Chile, 1993).

URZÚA, Germán, Evolución de la administración pública chilena (1818-1968) (Santiago, Editorial Jurídica de Chile, 1970).

WestermeYer, Felipe, Derecho indiano y derecho patrio en las "Memorias" de los ministros de Justicia de Chile (1839-1873), en REHJ., 32 (2011), pp. 533-581. 